\title{
Intussusception reveals MUTYH-associated polyposis syndrome and colorectal cancer: a case report
}

\author{
Gustavo Heluani Antunes de Mesquita ${ }^{1 *}$, Bárbara Justo Carvalho ${ }^{1}$, Kayo Augusto de Almeida Medeiros', \\ Fernanda Nii ${ }^{1}$, Diego Ramos Martines ${ }^{1}$, Leonardo Zumerkorn Pipek', Yuri Justi Jardim', Daniel Reis Waisberg², \\ Marcos Takeo Obara ${ }^{3}$, Roberta Sitnik ${ }^{3}$, Alberto Meyer ${ }^{2,3}$ and Cristóvão Luis Pitangueiras Mangueira ${ }^{4}$
}

\begin{abstract}
Background: We are reporting a rare case of MUTYH-associated polyposis, a colorectal cancer hereditary syndrome, diagnosticated after an intussusception. Colorectal cancer is an important cause of cancer related mortality that can be manifested by an intussusception, a rare occurrence in adults and almost always related to tumors. Approximately $5 \%$ of colorectal cancers can be attributed to syndromes known to cause hereditary colorectal cancer, such as MUTYHassociated polyposis, autosomal genetic syndrome associated with this disease.

Case presentation: We present the case of a 44 years old male, that sought medical consultation with a complaint of abdominal discomfort, that after five days changed its characteristics. The patient was sent to the emergency department were a CT-scan revealed intestinal sub-occlusion by ileocolic invagination. Right colectomy was carried out. The anatomicpathological examination revealed a moderately differentiated mucinous adenocarcinoma and multiples sessile polyps, which led to the suspicion of a genetic syndrome. In the genetics analysis two mutations were observed in the MUTYH gene, and MUTYH-associated polyposis was diagnosticated.

Conclusion: This case demonstrates the importance of meticulous analysis of the patient examinations results to identify possible discrete alterations that can lead to improved understanding of disease.
\end{abstract}

Keywords: MUTYH-associated polyposis, Intussusception, Hereditary colorectal cancer

\section{Background}

Colorectal cancer is the fourth most common, and the second biggest cause of cancer related mortality in the United States [1], with an estimated 1.4 million new cases diagnosed worldwide in 2012 [2]. Colorectal cancer predominantly affects males, and its incidence increases with age. Despite this, Bailey et al [3] highlight an increasing incidence in younger patients, between 20 and 34 years of age, which could increase by $90 \%$ for colon cancer and $124.2 \%$ for rectal cancer by 2030 . Obesity, diets rich in red meat and processed foods, tobacco consumption, alcoholism and the presence of inflammatory

\footnotetext{
* Correspondence: gustavo.heluani@gmail.com

${ }^{1}$ FMUSP, São Paulo, Brazil

Full list of author information is available at the end of the article
}

intestinal diseases are considered risk factors for incidence of colorectal cancer [4].

Approximately $30 \%$ of colorectal cancers present a relationship with inherited genetic factors, and 5\% are attributed to syndromes known to cause hereditary colorectal cancer [5]. Among these, we can highlight syndromes caused by mutations in the APC gene, such as familial adenomatous polyposis and Gardner syndrome; mutations in the DNA repair system, such as Lynch syndrome, mutations in the MUTYH gene, such as MUTYH-associated polyposis (MAP); as well as more uncommon syndromes such as type $\mathrm{X}$ colorectal cancer and Peutz-Jeghers syndrome [6].

MAP is an autosomal genetic syndrome associated with colorectal cancer. Carriers of the syndrome have a 43 to $100 \%$ lifetime risk of developing colorectal cancer. Diagnosis of the syndrome is made through

(c) The Author(s). 2019 Open Access This article is distributed under the terms of the Creative Commons Attribution 4.0 International License (http://creativecommons.org/licenses/by/4.0/), which permits unrestricted use, distribution, and reproduction in any medium, provided you give appropriate credit to the original author(s) and the source, provide a link to the Creative Commons license, and indicate if changes were made. The Creative Commons Public Domain Dedication waiver (http://creativecommons.org/publicdomain/zero/1.0/) applies to the data made available in this article, unless otherwise stated. 
discovery of biallelic pathogenic mutations of the MUTYH gene [7, 8].

Clinical presentation of the syndrome is highly variable; patients can present no polyps, up to hundreds of polyps with variable morphology $[9,10]$. Duodenal and gastric polyps may be present, as well as an increased risk of ovarian, bowel, breast and endometrial cancers. Another possible characteristic is the presence of tumors in the sebaceous glands, skin and other appendages, dental abnormalities and hypertrophy of the retinal pigment epithelium [11].

Patients with colorectal cancer can be asymptomatic, where the disease is detected via screening. They can also present symptoms and suspicious signs, such as blood in stools, weight loss, alteration of intestinal habits, abdominal pain and anemia; or even being admitted to emergency units with intestinal obstruction, peritonitis and acute gastrointestinal bleeding [12]. One of the forms of intestinal obstruction is intussusception, rare in adults, and almost always related to tumors $[13,14]$.

The objective of this article is to present the case of a patient diagnosed with MAP following intestinal intussusception associated with a colon adenocarcinoma.

\section{Case presentation}

A patient of male sex, 44 years of age, sought medical consultation with complaints of heartburn, epigastric fullness and regurgitation for approximately 15 days, which he related to diet and anxiety. The patient did not report nausea, vomiting or alteration of intestinal habits. He used pantoprazol without improvement. As a comorbidity, the patient presented dyslipidemia. As well as the symptoms complained about, the patient also presented multiple sebaceous cysts. There was no relevant family history.

Dyspeptic syndrome was suspected, and an upper digestive endoscopy and abdominal ultrasonography were requested. After five days, the patient presented alteration of symptoms, and was sent to the emergency department, where he reported colic pain of moderate intensity localized in the right flank and right iliac fossa.
Abdominal computerized tomography was carried out, which revealed intestinal sub-occlusion by ileocolic invagination, being extended to the beginning of the transverse colon. Also, the cecal appendix was thickened (Fig. 1).

Following diagnosis, surgical intervention to undo the invagination through laparoscopy was carried out, followed by right colectomy. The anatomic-pathological examination revealed a moderately differentiated mucinous adenocarcinoma (low grade), T3 N0 (0/39 lymph nodes evaluated) (stage $2 \mathrm{~A}$ ). Multiple sessile polyps measuring between $2 \mathrm{~mm}$ and $6 \mathrm{~mm}$ were also found, which led to the suspicion of a genetic syndrome associated with colorectal cancer (Fig. 2).

An immunohistochemical analysis of the tumor cells initially revealed immunoexpression of preserved proteins in the repair genes (MLH-1, MSH-2, MSH-6, PMS2), ruling out association with a microsatellite instability phenotype. A genetic panel was then used for genes associated with intestinal polypoid cancer. The APC and MUTYH genes were analyzed using a library prepared with a multiplexed PCR kit (Qiagen) and a library using conventional PCR and Nextera (Illumina). Both libraries were submitted to Next Generation Sequencing (NGS) on a MiSeq Sequencer (Illumina). Paired-end reads were aligned to a UCSC reference sequence (hg19) and processed with a bioinformatics pipeline developed in the laboratory. Both genes were completely sequenced, with at least $50 \mathrm{X}$ coverage in $100 \%$ bases, including all exons and $10 \mathrm{bp}$ of adjacent intronic regions.

Genetic analysis revealed an absence of mutations on the APC gene, excluding syndromes like familial adenomatous polyposis (FAP), attenuated FAP and Gardner syndrome [15]. There were two variants found on the MUTYH gene. The alterations found were c.536A > G p.(Tyr179Cys) on exon 7 and c.1147delC p.(Ala385Profe*23) on exon 12, both of them classified as pathogenic on ClinVar database. This genetic constitution (Table 1) is related to MUTYH-associated polyposis (MAP).

A diagnosis of a genetic syndrome related to colorectal cancer was made, and follow up according to the
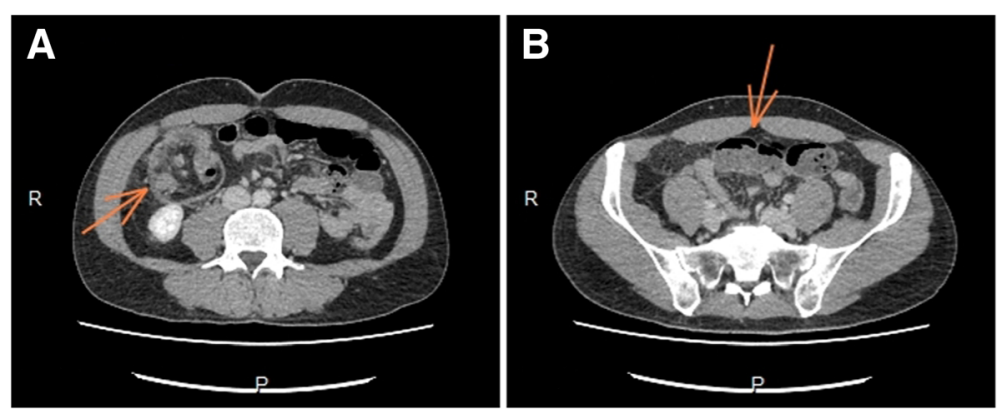

Fig. 1 Image from computerized tomography demonstrating a- ileocolic intussusception $\mathbf{b}$ - distention of the small intestine 


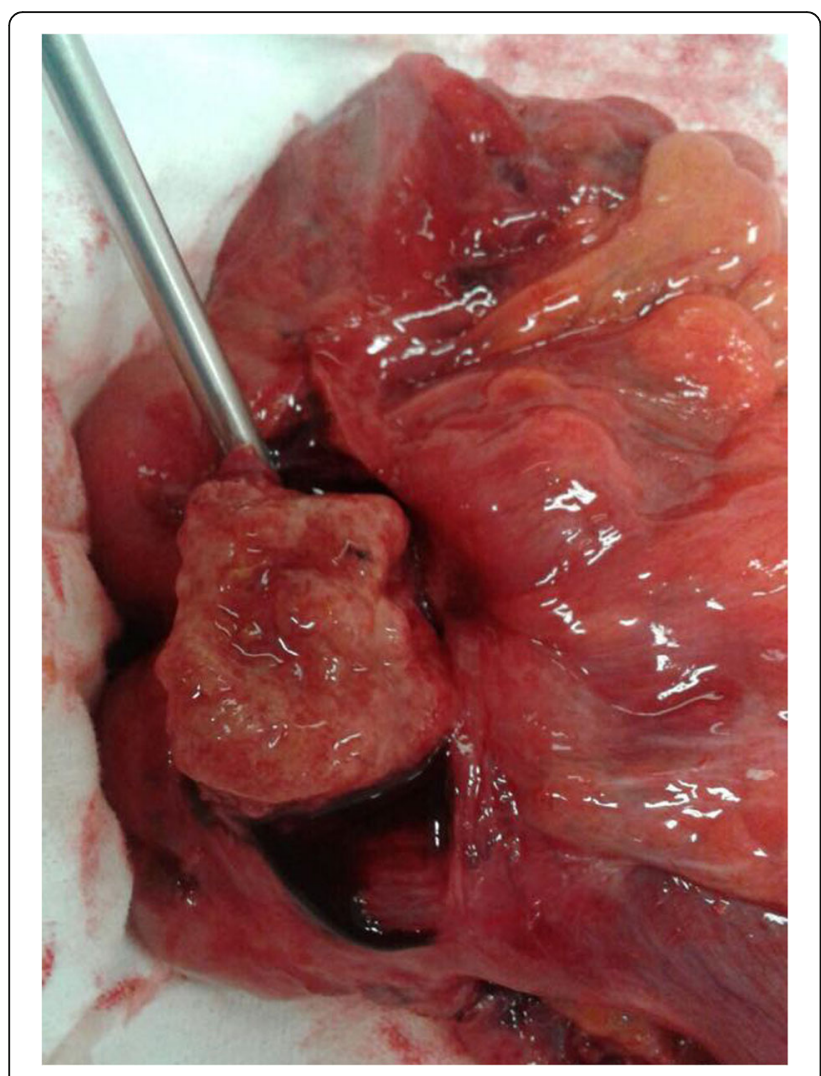

Fig. 2 Open cecum showing the tumor in its lumen

American Cancer Society guidelines was indicated. The first checkup was made three months after surgery, with thoracic and abdominal tomography, upper digestive endoscopy, colonoscopy and dosage of CEA. The results were within normal bounds, with a CEA of $<0.5$ and the presence of 6 tubular adenomas with a low degree of dysplasia in the colonoscopy, which were excised. Other colonoscopies were made 6 months after surgery and 1 year after surgery, resulting in the excision of 9 and 3 tubular adenomas with a low degree of dysplasia, respectively.

\section{Discussion}

MAP is a rare syndrome, responsible for less than $1 \%$ of cases of colorectal cancer [9], and despite high lifetime risk of developing colorectal cancer, these patients have a much higher 5-year survival rate than patients with sporadic colorectal cancer [16]. The clinical presentation of patients with MAP is highly heterogeneous, with a variable number and types of polyps. Our 44 year old patient had a form with few polyps, multiple sebaceous cysts, and no family history of the disease.

The diagnosis of colorectal cancer in our patient was made following 15 days of discomfort similar to dyspeptic syndrome. Abdominal pain, rare as the only symptom of colorectal cancer [17], intensified and changed, leading the patient to seek medical attention. A diagnosis of ileocolic intussusception was made, a rare condition in adults, but that in between 54.5 and 93.8\% [18-21] of cases is related to tumors.

Only $5 \%$ of intussusceptions occur in adults [14], being a rare occurrence. In the literature there is much disagreement about the percentage of cases that can be attributed to tumors, and the proportion of malignant tumors among them. In colonic intussusceptions, the percentage of malignant tumors is as high as 90\% [20]. Our patient is an example of intussusception being a manifestation of colorectal cancer. Due to the presence of multiple polyps on the surgical specimens, tests for genetic syndromes related to this malignancy were requested.

Case reports in the literature, such as ours, associate intussusceptions with tumors on the colon. Xie-qun [22] et al. and Gayatri Asokan [23] et al. report cases of patients that present to emergency services with obstructive symptoms, receiving a diagnosis of intussusceptions, and in surgery, tumors were considered of organic cause. Beyond the absence of diagnosed genetic syndromes, such cases differed from ours because of the patients' profiles; an older person in the first case and a patient with a more pronounced clinical presentation in the second, with rectal bleeding. Two other cases are reported by Manish Chand [24] et al., although the patients received diagnosis of colorectal cancer prior to that of intussusception, which occurred only in the intraoperative phase. In none of these cases was there suspicion of a genetic syndrome.

Schirier JC [25] et al. report MAP diagnosed in a 14 year old patient following intussusceptions. It is notable that in this age group, intussusception is a more frequent clinical manifestation [26], possibly due to the higher predisposition for intussusception in infancy. Such patients should be tested for genetic syndromes, and differ from our case due to the young age at which the patients develop tumors.

Jenifer M. Dan [27] et al. and Ryo Inada et al. [28], both present cases of intussusceptions in which the presence of genetic syndromes is associated with colorectal

Table 1 Details of variants found in MUTYH gene

\begin{tabular}{|c|c|c|c|c|c|}
\hline Gene & Variant & Exon & Population frequencie & Zigosity & Classification \\
\hline MUTYH (NM_001128425) & c.536A > G p.(Tyr179Cys) & 7 & $0,2153 \%$ & Heterozygous & Pathogenic variant \\
\hline MUTYH (NM_001128425) & c.1147delC p.(Ala385Profs*23) & 12 & $0,00752 \%$ & Heterozygous & Pathogenic variant \\
\hline
\end{tabular}


Table 2 literature case reports summary

\begin{tabular}{|c|c|c|}
\hline Case Report & Clinical presentation & Genetic Syndrome and Mutations \\
\hline Xie-qun et al & $\begin{array}{l}\text { 76yo male patient presented to emergency service } \\
\text { with obstructive simptoms }\end{array}$ & None \\
\hline Gayatri Asokan et al & $\begin{array}{l}\text { 36yo female patient presented to emergency service } \\
\text { with obstructive simptoms }\end{array}$ & None \\
\hline Manish Chand et al & $\begin{array}{l}\text { Adult patients diagnosed with colorectal cancer, } \\
\text { with intraoperative intussusception }\end{array}$ & None \\
\hline Schirier JC et al & $\begin{array}{l}\text { 14yo male patient presented to emergency service } \\
\text { with obstructive simptoms }\end{array}$ & $\begin{array}{l}\text { Mutyh associated polyposis - mutations } \\
\text { not specified }\end{array}$ \\
\hline Jenifer M Dan et al & 27yo male patient with intermitent intussuception & None \\
\hline Ryo Inada et al & 24yo male patient with abdominal pain and tenesmus & Tested negative for Lynch Syndrome \\
\hline
\end{tabular}

cancer. Both cases were young patients; 27 years old and 24 years old respectively. In the first case, due to the absence of synchronic polyps, the hypothesis was disregarded and genetic testing was not carried out. In the second case, analysis was carried out only for Lynch syndrome. In our patient, suspicion of genetic syndrome was raised not by the age of the patient, but because of the presence of synchronic polyps in the surgical specimen, from which a diagnosis of MAP was made. In related studies, genetic syndromes were possibly not diagnosed because the tests were not completely carried out. In the first case, the patient could have presented an attenuated form, without the presence of synchronic polyps, while in the second, other syndromes not tested for could have been diagnosed. A case reports summary is available in Table 2.

Patients with hereditary syndromes related to colorectal cancer needs accurate colonoscopy examinations because of the risk of polyps developing into colorectal cancer. Therefore, the completion rate of a colonoscopy is an important aspect, since that it guarantees a full examination of patients colon, increasing the chance of all polyps excision $[29,30]$. In our case report, the patient was submitted to colonoscopy 3 months, 6 months, and 1 year after surgery, with the excision of 6,9 and 3 tubular adenomas with a low degree of dysplasia, respectively.

Our case presented some particularities that differed from other reported cases, as it was an adult patient diagnosed with a genetic syndrome and colorectal cancer following intussusception. It is notable that the patient presented an attenuated form of polyposis and the presence of multiple sebaceous cysts, one of the clinical variants of MAP. An important aspect is that the diagnosis was only possible because there was a meticulous analysis of the patients anatomic-pathological exam, where multiple sessile polyps were found. This finding led to the suspicious of an hereditary syndrome. The perseverance in the genetic analysis after negative results for FAP, attenuated FAP and Gardner syndrome is another important aspect, since MAP was only diagnosed because it was decided to test for other rare syndromes related to colorectal cancer.

\section{Conclusion}

This case demonstrates the importance of meticulous analysis of the patient examinations results to identify possible discrete alterations that can lead to improved understanding of disease, and tailored treatment for patients accordingly. The discovery and analysis of polyps led to the diagnosis of an underlying genetic condition that altered follow up strategy for the patient.

\section{Abbreviations \\ CEA: Carcinoembryonic antigen; FAP: Familial adenomatous polyposis; MAP: MUTYH-associated polyposis}

\section{Acknowledgments \\ The authors are thankful to and to Justin Axel-Berg for english corrections. \\ Funding \\ No funding source was used. \\ Availability of data and materials \\ All data produced and obtained is available within the manuscript.}

\section{Authors' contributions}

GHAM, BJC and KAAM were responsible for study design and writing. FN, DRR, LZP, YJJ were responsible for data collections and data analysis. AM, RS, CLPM, MTO and DRW were involved in the study design and were responsible for scientific revision. All authors read and approved the final manuscript.

\section{Ethics approval and consent to participate}

The study was approved on Hospital Israelita Albert Einstein ethical committee and informed consent was obtained from all individual participants included in the study.

\section{Consent for publication}

Written consent was obtained from each patient authorizing to publish their individual data or any accompanied figures in this manuscript.

\section{Competing interests}

The authors declare that they have no competing interests.

\section{Publisher's Note}

Springer Nature remains neutral with regard to jurisdictional claims in published maps and institutional affiliations.

\section{Author details}

${ }^{1}$ FMUSP, São Paulo, Brazil. ${ }^{2}$ Departamento de Gastroenterologia, Hospital das Clínicas, HCFMUSP, São Paulo, Brazil. ${ }^{3}$ Hospital Israelita Albert Einstein, São Paulo, Brazil. ${ }^{4}$ Diretor do Departamento de Patologia Clínica e Anatomia Patológica do Hospital Israelita Albert Einstein, São Paulo, Brazil. 
Received: 16 July 2018 Accepted: 21 March 2019

Published online: 05 April 2019

\section{References}

1. American Cancer Society. Cancer Statistics Center. http:// cancerstatisticscenter.cancer.org. Accessed 1 Mar 2018.

2. Ferlay J, Soerjomataram I, Ervik M, Dikshit R, Eser S, Mathers C, Rebelo M, Parkin DM, Forman D, Bray FGLOBOCAN. v1.1, Cancer incidence and mortality worldwide: IARC CancerBase no. 11 [internet]. Lyon. France: International Agency for Research on Cancer; 2012. p. 2014.

3. Bailey CE, Hu C-Y, You YN, et al. Increasing disparities in age-related incidence of Colon and Rectal Cancer in the United States, 1975-2010. JAMA Surgery. 2015;150(1):17-22. https://doi.org/10.1001/jamasurg.2014.1756.

4. Colorectal cancer facts \& figures 2014-2016. Atlanta: American Cancer Society, 2014 (http://www.cancer.org/acs/groups/content/documents/ document/acspc-042280.pdf).

5. Patel SG, Ahnen DJ. Familial Colon Cancer syndromes: an update of a rapidly evolving field. Curr Gastroenterol Rep. 2012;14(5):428-38. https://doi. org/10.1007/s11894-012-0280-6.

6. Lung MS, Trainer AH, Campbell I, Lipton L. Familial colorectal cancer. Intern Med J. 2015;45:482-91. https://doi.org/10.1111/imj.12736.

7. Al-Tassan N, Chmiel NH, Maynard J, Fleming N, Livingston AL, Williams GT, Hodges AK, Davies DR, David SS, Sampson JR, Cheadle JP. Inherited variants of MYH associated with somatic G:C-->T:a mutations in colorectal tumors. Nat Genet. 2002;30:227-32.

8. Sereno M, Merino M, López-Gómez M, et al. Clin Transl Oncol. 2014;16:675. https://doi.org/10.1007/s12094-014-1171-0.

9. Cleary SP, Cotterchio M, Jenkins MA, Kim H, Bristow R, Green R, Haile R, Hopper JL, LeMarchand L, Lindor N, Parfrey P, Potter J, Younghusband B, Gallinger S. Germline MutY human homologue mutations and colorectal cancer: a multisite case-control study. Gastroenterology. 2009;136:1251-60.

10. Sieber OM, Lipton L, Crabtree M, Heinimann K, Fidalgo P, Phillips RK, Bisgaard ML, Orntoft TF, Aaltonen LA, Hodgson SV, Thomas HJ, Tomlinson IP. Multiple colorectal adenomas, classic adenomatous polyposis, and germline mutations in MYH. N Engl J Med. 2003;348:791-9.

11. Brand R, Nielsen M, Lynch H, Infante E. MUTYH-Associated Polyposis. Gene Reviews. Funded by the $\mathrm{NIH}$. Developed at the University of Washington, Seattle. Initial Posting: October 4, 2012. Accessed 8 Mar 2018. Available at URL address: http://www.ncbi.nlm.nih.gov/books/NBK107219/

12. Majumdar SR, Fletcher RH, Evans AT. How does colorectal cancer present? Symptoms, duration, and clues to location. Am J Gastroenterol. 1999;94: 3039-45.

13. Lu T, Chng YM. Adult Intussusception. Perm J. Winter. 2015;19(1):79-81. https://doi.org/10.7812/TPP/14-125.

14. Chiang J-M, Lin Y-S. Tumor spectrum of adult intussusception. J Surg Oncol. 2008;98:444-7. https://doi.org/10.1002/jso.21117.

15. Jasperson KW, Tuohy TM, Neklason DW, Burt RW. Hereditary and familial colon cancer. Gastroenterology. 2010;138(6):2044-58. https://doi.org/10. 1053/j.gastro.2010.01.054.

16. Nielsen $M$, van Steenbergen $L N$, Jones $N$, et al. Survival of MUTYH-associated polyposis patients with colorectal Cancer and matched control colorectal Cancer patients. JNCI J Natl Cancer Inst. 2010;102(22):1724-30. https://doi. org/10.1093/jnci/djq370.

17. Thompson MR, O'Leary DP, Flashman K, Asiimwe A, Ellis BG, Senapati A. Clinical assessment to determine the risk of bowel cancer using symptoms, age, mass and Iron deficiency anaemia (SAMI). Br J Surg. 2017;104:1393-404. https://doi.org/10.1002/bjs.10573.

18. Oliveira LT, Essu FF, de Mesquita GHA, et al. Component separation of abdominal wall with intraoperative botulinum A presents satisfactory outcomes in large incisional hernias: a case report. Int J Surg Case Rep. 2017;41:99-104.

19. Wang N, Cui X-Y, Liu Y, et al. Adult intussusception: a retrospective review of 41 cases. World J Gastroenterol. 2009;15(26):3303-8. https://doi.org/10. 3748/wjg.15.3303.

20. Honjo H, Mike M, Kusanagi $H$, Kano N. Adult intussusception: a retrospective review. World J Surg. 2015;39:134-8. https://doi.org/10.1007/s00268-0142759-9.

21. Eisen LK, Cunningham JD, Aufses AH Jr. Intussusception in adults: institutional review. J Am Coll Surg, 188. 1999;e5:390.
22. Xu X-Q, Hong T, Liu W, Zheng C-J, He X-D, Li B-L. A long adult intussusception secondary to transverse colon cancer. World J Gastroenterol. 2013;19(22):3517-9. https://doi.org/10.3748/wjg.v19.i22.3517.

23. Asokan $G$, Hollington P. Sigmoid malignancy presenting as recto-sigmoid intussusception. ANZ J Surg. 2014;84(5):386-7. https://doi.org/10.1111/ans. 12232.

24. Chand M, Bradford L, Nash GF. Intussusception in colorectal Cancer. Clin Colorectal Cance. 2008;7(3):204-5. https://doi.org/10.3816/CCC.2008.n.028.

25. Schrier JC, Ouwehand F, Aronson DC, Booij KA, Benninga MA, Verbeek PC. A colo-colic invagination on the basis of MutYH-associated polyposis in a boy aged 14. Nederlands Tijdschrift Voor Geneeskunde. Ned Tijdschr Geneeskd. 2007;151(28):1589-92.

26. Cohen S, Gorodnichenco A, Weiss B, Lerner A, Ben-Tov A, Yaron A, Reif S. Polyposis syndromes in children and adolescents: a case series data analysis. Eur J Gastroenterol Hepatol. 2014;26(9):972-7. https://doi.org/10.1097/MEG. 0000000000000143.

27. Dan JM, et al. Adult Intussusception Secondary to Colorectal Cancer in a Young Man: A Case Report. J Emerg Med. 2012;43(6):983-6.

28. Inada R, Nagasaka T, Toshima T, et al. Intussusception due to rectal adenocarcinoma in a young adult: a case report. World J Gastroenterol: WJG. 2014;20(35):12678-81. https://doi.org/10.3748/wjg.v20.i35.12678.

29. Journal of Medicine and Life Vol. 4, No1, January-March 2011, pp.109-111.

30. Diseases of the Colon \& Rectum: April 2009 - Volume 52 - Issue 4 - p 742-745.

\section{Ready to submit your research? Choose BMC and benefit from:}

- fast, convenient online submission

- thorough peer review by experienced researchers in your field

- rapid publication on acceptance

- support for research data, including large and complex data types

- gold Open Access which fosters wider collaboration and increased citations

- maximum visibility for your research: over $100 \mathrm{M}$ website views per year

At $\mathrm{BMC}$, research is always in progress.

Learn more biomedcentral.com/submissions 